\title{
A PESQUISA CIENTÍFICA COMO METODOLOGIA NO ENSINO JURÍDICO
}

\author{
SCIENTIFIC RESEARCH AS METHODOLOGY OF LEGAL EDUCATION
}

\author{
Nivaldo dos Santos ${ }^{1}$ \\ Thiago Alexandre Ribeiro Santana ${ }^{2}$
}

\begin{abstract}
Resumo
$\mathrm{O}$ artigo sustenta a tese da educação pela pesquisa. O texto parte de uma análise da atual realidade do ensino jurídico nacional e verifica que dentre os principais problemas da crise institucional da educação jurídica a política didático-pedadógica desenvolvida pelas Faculdades de Direito é a grande responsável pela continuidade dos desempenhos acadêmicos insatisfatórios. A metodologia do ensino jurídico brasileiro é pautada por métodos e técnicas de ensino que interditam uma aprendizagem de alto impacto e reforçam a reprodução acrítica do conhecimento. $\mathrm{O}$ estudo constatou que as instituições de ensino jurídico com elevado padrão de qualidade e máxima eficiência didática estão sustentadas por uma plataforma educacional com fundamento metodológico na educação pela pesquisa. A pesquisa como recurso metodológico de ensino cria uma dimensão educacional altamente produtiva e com níveis de excelência acadêmica.
\end{abstract}

Palavras-Chaves: Educação; Ensino Jurídico; Metodologia do Ensino Jurídico; Pesquisa Científica.

\begin{abstract}
The article states the thesis of education by research. The text part of an analysis of the current reality of the national legal education and notes that among the main problems of the institutional crisis of juridical education didactic and pedagogic policy developed by Law Schools as largely responsible for the continuation of unsatisfactory academic performance. The methodology of the Brazilian legal education is guided by teaching methods and techniques to interdict a high-impact learning and reinforce the uncritical reproduction of knowledge. The study found that the legal education institutions with high quality standards and maximum teaching efficiency are supported by an educational platform with methodological foundation in education by research. The research as a methodological resource teaching creates a high productive educational dimension and with levels of academic excellence.
\end{abstract}

Keywords: Education; Legal Education; Methodology of Legal Education; Scientific Research.

\footnotetext{
${ }^{1}$ Doutor em Direito pela Pontifícia Universidade Católica de São Paulo. Professor Titular da Universidade Federal de Goiás e da Pontifícia Universidade Católica de Goiás. Coordenador do Núcleo de Patentes e Transferência de Tecnologia do Estado de Goiás. Coordenador da Rede Estadual de Pesquisa em Propriedade Intelectual e Transferência de Tecnologia do Estado de Goiás - REPPITTEC/FAPEG. e-mail: nivaldodossantos@bol.com.br

${ }^{2}$ Mestre em Filosofia pela Universidade Federal de Goiás. e-mail: tars.br@gmail.com
}

R. Fac. Dir. UFG, v. 38, n. 2, p. 284-301, jul. /dez. 2014 


\section{Introdução}

No cenário contemporâneo o conhecimento científico e tecnológico multiespecializado constitui elemento fundamental na composição do sistema produtivo vigente assentado em um modelo econômico de acumulação flexível, cujas variáveis impactam diretamente na configuração da geopolítica internacional. Na sociedade da informação e do conhecimento $^{3}$, as relações interpessoais e institucionais estão sendo sistematicamente alteradas pela ostensiva valorização do capital intelectual e pelas novas demandas e tendências criadas pelo mercado globalizado que exige de modo constante o fluxo renovado de recursos humanos altamente qualificados.

Essa realidade mundial intensifica os níveis de exigência da missão institucional da Universidade que deve estar invariavelmente comprometida com a busca de excelência na pesquisa científica, na inovação tecnológica e na produção de novos conhecimentos, de forma concomitante ao desenvolvimento de uma educação superior de elevada qualidade. Em razão deste pressuposto, todas as instâncias acadêmicas têm a responsabilidade social de prospectar eficientes mecanismos de aperfeiçoamento do ensino e da pesquisa que devem sustentar o processo de formação das novas gerações.

Nesta senda, as Faculdades de Direito comprometidas com os mais elevados padrões educacionais tem o dever institucional de articular políticas acadêmicas pautadas por rigorosos critérios técnicos que colaborem no desenvolvimento de novos saberes jurídicos, na reformulação dos métodos de conhecimento do Direito, na atualização dos valores consagrados pela tradição secular e, em especial, na formação competente de novos juristas qualificados a pensar soluções inovadoras para os atuais problemas jurídicos intricados na complexa rede de demandas do paradigma emergente ${ }^{4}$.

\footnotetext{
${ }^{3} \mathrm{O}$ termo refere-se ao conjunto de transformações estruturais ocorridas no mundo após a terceira revolução industrial, ainda em curso, na qual a informação e o conhecimento tecnocientífico foram elevados a um novo patamar valorativo e estratégico na organização dos arranjos econômicos e sociopolíticos da comunidade global.

${ }^{4}$ A acepção paradigma emergente defluiu da crise instaurada no modelo dicotômico, linear e determinista de racionalidade científica do paradigma dominante, que é insuficiente para a composição de conhecimentos racionais sustentáveis em face das complexidades paradoxais, imprevisibilidades e incertezas do contexto pós-moderno.
} 
À luz desta perspectiva propomos analisar a importância da pesquisa científica enquanto recurso metodológico de ensino e instrumento diretivo das ações de qualificação da educação jurídica brasileira.

\section{Panorama da Realidade Educacional das Faculdades de Direito}

O levantamento dos dados aferidos pelo Sistema Nacional de Avaliação da Educação Superior - Sinaes, indica o crescimento vertiginoso de um processo degenerativo da qualidade do ensino superior brasileiro, especialmente se comparado com os resultados apresentados pelos mais conceituados parâmetros internacionais de avaliação da excelência universitária que ponderam como critérios de análise o desempenho acadêmico, a repercussão das pesquisas científicas, as premiações, a qualidade das publicações e o impacto das inovações e tecnologias desenvolvidas pelas instituições de ensino superior.

No quadro complexo que se encontra a educação superior nacional tornou-se gradativamente reconhecido no meio social e comprovado pelas estatísticas e indicadores de qualidade organizados sob a responsabilidade das entidades educacionais e jurídicas mais respeitadas do país que, o atual modelo de ensino jurídico personifica por múltiplas razões a imagem mais representativa da crise do ensino superior ${ }^{5}$, cujos efeitos simbólicos são a fragmentação e a deterioração dos elevados valores e virtudes que alicerçam e dignificam o ambiente acadêmico (universitas scientiarum), entendido secularmente como o espaço de engrandecimento da cultura e do saber científico.

O mapeamento da realidade educacional das Faculdades de Direito brasileiras apresenta como elemento descritor generalizante a intensiva reprodutividade do conhecimento

\footnotetext{
${ }^{5}$ A expressão crise do ensino superior reverbera per si a confluência de múltiplos fatores e fenômenos que produziram a série de problemas estruturais, administrativos e pedagógicos que se encontram emaranhados no processo histórico de formação do ensino universitário brasileiro, cujos efeitos culminaram, no último século, na elaboração de um conjunto de medidas governamentais voltadas à reforma da educação superior. Sendo que, nos idos da década de 70, as reformas promovidas no ensino superior ampliaram a valorização da Universidade na medida em que a formação profissional superior correspondia a prestígio e elevação da condição social. Na década seguinte, houve o início da expansão desenfreada da rede privada de ensino superior, sem o devido rigor na qualidade, justificada pela necessidade de aumentar a formação de recursos humanos para o mercado. A partir dos anos 90, com a redução das competências estatais, em prol do setor privado, as políticas de educação superior começaram a ser formuladas sob o crivo de processos de gerenciamento empresarial, no que a Universidade passa a ser entendida como mera entidade administrativa regulada por estratégias de eficácia organizacional. A consequência desta reestruturação operacional do ensino superior está no fato atual de que a Universidade gradua profissionais com inúmeras deficiências de conhecimento, competências e habilidades. Conforme análise de Chauí: "A universidade, exatamente como a empresa, está encarregada de produzir incompetentes sociais, presas fáceis da dominação e da rede de autoridades (...) tanto menos se deve ensinar e tanto menos se deve aprender" (2001, p. 55).
}

R. Fac. Dir. UFG, v. 38, n. 2, p. 284-302, jul. /dez. 2014 
jurídico oficial. As instituições de ensino jurídico, em sua expressiva maioria, representam meros centros de treinamento técnico forjados sob a égide de uma mentalidade compulsiva pela simplificação e reprodução acrítica do fenômeno jurídico, cuja finalidade é dinamizar o processo de automação da preparação profissional realizado em larga escala para atender as superfluidades do mercado.

Neste tipo de ambiente educacional dominado pela visão estática e acumulativa de ciência $^{6}$, em que a idéia de aquisição de conhecimentos está radicalmente assentada em um projeto arcaico de educação que privilegia em grau superlativo os esquemas de memorização, as técnicas de repetição sistemática e a aprendizagem descontextualizada, é inevitável a formação de sujeitos despreparados para o questionamento crítico, o pensar autônomo, a elaboração de soluções criativas e a reconstrução do conhecimento e da cultura. Em face desta realidade educacional afirma Nicolás Calera:

\begin{abstract}
Defenderá la necesidad de que las Facultades de Derecho, como la Universidad en general, recuperen su vieja y auténtica categoría y naturaleza de centros de cultura superior y dejen de ser escuelas de formación profesional. Reconozco que ésta es, por ahora, una gran utopía, pero tal vez la dinámica de los hechos (...) conduzca a esa nueva situación universitaria, en la que se enseñará y se aprenderá sin las obsesiones de los títulos profesionales y de la rentabilidad social inmediata. Entonces las Facultades de Derecho asumirán un profundo sentido liberador y no dejarán por ello de servir, sin las degradaciones e integraciones alienantes de hoy, a la preparación de los profesionales que la sociedad, no el sistema, necesita (CALERA, 1980-1981, p. 40)
\end{abstract}

O modelo de ensino jurídico standard ${ }^{7}$ constitui uma espécie de virulência introjetada nas Faculdades de Direito brasileiras, cujo resultado é a produção polimórfica de condições negativas para uma formação educacional e cultural de elevada qualidade. A estrutura vigente modela um tipo de jurista ontologicamente fragmentado, portador de saberes humanísticos, científicos e técnico-jurídicos incipientes, que são incompatíveis com as exigências profissionais e com as expectativas sociais. As graduais deformações do processo educacional jurídico conduziram a formação de um contingente de bacharéis acostumados a

\footnotetext{
${ }^{6}$ A noção tradicional de ciência vertida na idéia de um sistema fechado de verdades acumuladas em compartimentos está sendo gradativamente alterada por uma concepção mais dinâmica, na qual o discurso das teorias científicas é entendido como um modelo explicativo provisório da complexa realidade. Nas ponderações de Morin (2003) a forma de desenvolvimento científico moderno, governada pela razão instrumental, mostra-se ineficiente face à multiplicidade de novos arranjos na teia da vida planetária, exigindo assim a elaboração de modelos científicos mais versáteis com fundamento em pensamentos complexos que possam transitar pelas incertezas e imprevisibilidades do presente e do futuro.

7 Para Inês Pôrto (2000, p. 33) a situação crítica das Faculdades de Direito pode ser entendida a partir dos elementos representativos do "modelo central" de educação jurídica atualmente padronizado, cujas características principais são a descontextualização, o dogmatismo e a unidisciplinaridade.
}

R. Fac. Dir. UFG, v. 38, n. 2, p. 284-302, jul. /dez. 2014 
operações mentais de reduzida complexidade, idéias autoevidentes, argumentos retóricos, falta de rigor metodológico, culto excessivo da forma e ao discurso de autoridade.

\begin{abstract}
Por isso mesmo, impõe-se outorgar ao ensino jurídico uma nova fisionomia calcada em densidade teórica, crítica e técnica, com objetivo de fugir do jargão que tem caracterizado a maioria das escolas de Direito, tidas como centros reprodutores de conhecimento codificados, em prejuízo das atividades criadoras, das funções críticas e das finalidades de produção científica e da elaboração reflexiva do pensamento jurídico (FILHO, 1997, p. 121)
\end{abstract}

A educação jurídica nacional encontra-se imersa em uma crise institucional cujos feixes de justificação reportam a uma série de fatores de natureza endógena e exógena que estão interconectados ${ }^{8}$. Na face exógena, há uma plêiade de novas e controvertidas demandas de caráter sociopolítico, econômico, tecnológico e multicultural que foram originadas na base do paradigma emergente e que confrontam as clássicas concepções de Direito e de Justiça, entreabrindo assim, a visceral necessidade de composição de novos domínios teóricos e metodológicos capazes de sustentar conhecimentos jurídicos inovadores compatíveis com o nível das demandas contemporâneas. Segundo José Eduardo Faria:

o ensino jurídico se destaca pelo flagrante envelhecimento de seus esquemas cognitivos e pelo esgotamento de seus paradigmas teóricos. Por isso tornou-se incapaz de identificar e compreender a extrema heterogeneidade dos novos conflitos sociais, a enorme complexidade técnica das novas normas, a interdependência cada vez mais presente no funcionamento da economia, os valores, as demandas e as expectativas por ela gerados na sociedade e a emergência de um sem-número de novas fontes de Direito com a preeminência dos conglomerados transnacionais como atores internacionais (FARIA in GUSTIN \& DIAS, 2002, p. 2)

Noutro vértice, encontram-se dispostos os elementos de natureza endógena que concorrem interinamente para a crise do sistema de educação jurídica do país. Dentre as variadas razões que explicam a sintomática redução da qualidade educacional das Faculdades de Direito estão os problemas concernentes à infraestrutura material ${ }^{9}$, estrutura acadêmica ${ }^{10}$,

\footnotetext{
${ }^{8}$ A compreensão global da crise do ensino jurídico exige uma análise dialética que considere a conexão lógica dos seus fatores internos e externos, conforme explica Horário Wanderley Rodrigues: "A não compreensão de seu aspecto multifacético, que atinge diversas instâncias e níveis, é um dos problemas centrais que reveste muitas das respostas que vem sendo apresentadas" (1995, p. 17).

${ }^{9}$ Falta de espaço físico neuroestimulador, salas de aulas adequadas, salas de reunião, gabinetes dos professores, auditórios, escritórios modelos, equipamentos informatizados, bibliotecas com acervo atualizado de obras nacionais e estrangeiras.

${ }^{10}$ Deficiências no funcionamento da direção e dos órgãos colegiados, na secretaria do curso, na preparação do quadro técnico-administrativo, no planejamento das atividades acadêmicas, na gestão do curso e no sistema de avaliação (institucional, docente e discente). Por vezes, é inexistente o desenvolvimento de políticas de mobilidade acadêmica, parcerias com instituições de credibilidade, incentivo à pesquisa e à publicação.
} 
corpo docente ${ }^{11}$, organização curricular $^{12}$ e a política didático-pedagógica. Embora esta conjuntura negativa seja resultante da combinação de todos os fatores que concorrem para reforçar a permanência do quadro crítico instalado nas escolas de Direito, é inevitável o reconhecimento de que a seara didático-pedagógica comporta a faceta mais problemática desta crise sistêmica da educação jurídica nacional. A esfera didático-pedagógica constitui a espinha dorsal que sustenta o projeto epistemológico de educação e possibilita a articulação das estratégias educacionais da relação de ensino-aprendizagem.

No campo juspedagógico prevalece um fenômeno anacrônico de hipervalorização do modelo tradicional de educação ${ }^{13}$ cuja visão unidimensional de formação humana é moldada pelo predomínio da máxima transmissão de conteúdos, rigorosa verticalização da relação professor-transmissor e aluno-receptor, excessiva descrição acrítica $^{14}$ do objeto cognoscível e a redução do saber à noção acumulativa de conhecimentos. No plano didático, as diretrizes do modelo pedagógico tradicional sacralizaram o método expositivo balizado na aula-conferência ${ }^{15}$ em que o docente deve realizar preleções magistrais, no formato de um curso-monólogo, que, raras às vezes, não infesta o ambiente acadêmico de uma retórica formalista ${ }^{16}$ saturada de superficialidades e trivialização da cultura jurídica.

La descripción del derecho en nuestras escuelas, está sobresaturado de estereotipos, expresiones fabuladoras, términos significativamente anémicos, rectificaciones, argumentos retóricos y concesiones metafísicas. Ello conforma, sin duda, un proceso de socialización normativa, altamente dogmático y persuasivo (...). Como resultado de ello, producimos en nuestras facultades, un tipo de profesional que carece de instrumental teórico apto para problematizar el sistema jurídico aprendido

\footnotetext{
11 Déficit na titulação, na competência científica e pedagógica, vocação, dedicação, produção acadêmica qualificada, participação em eventos científicos e culturais. Persistem também problemas relativos à contratação por seleção pública, regime de trabalho, criação de programas de capacitação e progressão na carreira por mérito acadêmico.

${ }^{12}$ Falta de organicidade curricular, diálogo interdepartamental, integração de temas transdisciplinares, desenvolvimento de atividades extracurriculares, exigência de trabalhos monográficos e flexibilidade nos estágios.

${ }^{13}$ De acordo com Pimenta \& Anastasiou: "no enfoque tradicional ou prático-artesanal, a finalidade do ensino é a de transmitir os conhecimentos diretamente vinculados às habilidades para fazer coisas ou objetos e aos modos, usos, costumes, crenças e hábitos, reproduzindo-os e, portanto, conservando os modos de pensar e agir tradicionalmente consagrados e socialmente valorizados" (2002, p. 183).

${ }^{14}$ A respeito do tema João Maurício Adeodato analisa: "O problema do direito são os relatos descritivos do direito positivo que caracterizam aulas, cursos e produção bibliográfica. A própria qualidade do exame de ordem e dos concursos públicos vai na mesma direção. Não se problematiza, não se ensina a pensar" (2007, p. 134).

15 Para Álvaro Melo Filho, a aula-conferência é "responsável maior pelas rotinas ineficazes e pela castração intelectual dos alunos, que, condenados ao silêncio são compelidos a um comportamento passivo e não-questionador, num desestímulo a qualquer reflexão crítica" (1997, p. 118).

${ }^{16}$ A ação didática revestida de formalismo provoca danos radicais na formação intelectual, pois, o educando realiza uma operação de apreensão da sintaxe lógica de um objeto do conhecimento, suas fórmulas externas; mas, não consegue inteligir no nível de uma inferência conceitual do objeto cognoscível, compreendendo o seu conteúdo. Segundo Nílson Machado, o ato de compreender é "apreender o significado de um objeto ou de um acontecimento; é vê-lo em suas relações com outros objetos ou acontecimentos; os significados constituem, pois, feixes de relações que, por sua vez, se entretecem, se articulam em teias, em redes, construídas socialmente e individualmente, e em permanente estado de atualização" (1995, p. 21).
} 
secularmente como incuestionable, natural, lógicamente riguroso, con instituciones perfectas y órganos neutros, ideológicamente descomprometidos. Las escuelas de derecho brindan de esta forma la posibilidad de forjar las ilusiones del jurista con respecto a su propia actividad, sin buscar ni producir aquellos elementos analíticos que le permitan elevarse a la comprensión teórica del fenómeno normativo en su conjunto y dentro de un tiempo histórico específico (WARAT, 1976, p. 165-166)

A incorporação desta fórmula didático-pedagógica no âmbito das Faculdades de Direito maximizou o quadro de deterioração institucional da educação jurídica, na medida em que instrumentalizou o ensino com um suporte metodológico que reforça o procedimento alienante de reprodução acrítica do conhecimento jurídico. Pari passu, subvencionou a existência de uma mentalidade com pretensões de cientificidade que tem percorrido os subterrâneos da cultura jurídica e da produção acadêmica hodierna. Essa mentalidade é o substrato constitutivo do senso comum teórico ${ }^{17}$ dos juristas, o qual arquitetou uma dimensão paralela composta de suposições, conjecturas, juízos, opiniões, estereótipos e arranjos argumentativos legitimados pelo empirismo institucional forense. $\mathrm{O}$ senso comum teórico reveste o imaginário dos juristas com um forte componente ideológico ${ }^{18}$ que influencia a produção dos discursos jurídicos e o campo educacional.

Um ensino ao nível do senso comum teórico, tal como hoje se pratica entre nós, termina deste modo por atribuir significações discutíveis e arbitrárias da realidade social, projetando-as imaginariamente como possíveis e desejáveis, ainda que nem sempre factíveis, plasmando-as em discursos reificantes, a-históricos e com pretensão de generalidade e universalidade. Em vez de apresentar institutos jurídicos como formas de soluções de conflitos com raízes no processo das relações sociais, valoriza-se quase que exclusivamente uma abordagem sistemática e lógico-dedutiva, privilegiando-se o princípio da autoridade - isto é, a opinião dos "preclaros mestres", dos "insígnes doutores", dos "notáveis educadores", dos "doutos colegas", todos muitas vezes citados aos borbotões e usados como pretexto para demonstração de uma erudição sem peso teórico, recheando manuais e livros - isto quando não servindo para engrossar teses acadêmicas de professores pouco criativos e sem inspiração, abrindo caminho para que o "pedantismo de ligeireza" sirva de critério para o prevalecimento, no âmbito do corpo docente, de um tipo modal de mestre acrítico, burocrático e subserviente aos clichês e estereótipos predominantes entre os juristas de ofício (FARIA, 1987, p. 47)

\footnotetext{
${ }^{17}$ Para o mentor intelectual desta abordagem conceitual, Luis Alberto Warat (2004), o senso comum teórico comporta planos topicamente setorizados, tais como, o das opiniões éticas, o das crenças ideológicas, epistemológicas e dos conhecimentos vulgares, que, coordenados, atuam na esfera subjetiva dos juristas formatando um nonsense jurídico-científico.

${ }^{18} \mathrm{O}$ pensamento ideológico deturpa o rigor de uma análise crítica dos fenômenos complexos e suas conexões, ao se colocar como princípio explicativo mais amplo e importante do que realmente é. A respeito da faceta tipicamente acrítica do pensamento ideológico, Reinhold Zippelius escreve: "Dabei wird sich unkritisches Denken leicht dazu verleiten lassen, auf einen einmal isolierten und für erheblich befundenen Faktor (z.B. die ökonomischen Bedingungen, die Rasse, den Willen zur Macht) allzu viel zurückzuführen, ihn also für ein umfassenderes Erklärungsprinzip zu halten, als er in Wahrheit ist. Das ist das Kennzeichen und der Fehler zumal des ideologischen Denkens" (1999, p. 11).
} 
As Faculdades de Direito brasileiras ainda estão estruturadas sobre os pilares de uma política acadêmica reacionária à projeção de um ambiente educacional indutor da criação, da inovação, da experimentação científica e da produção qualificada de conhecimentos. O establisment acadêmico ancora-se numa plataforma de ensino jurídico caracterizada pelo viés autoritário, massificador e dogmático, que delineia o programa-padrão de formação jurídica atual, no qual impera a falta de reflexão crítica, rigor metodológico, densidade teórica, argumentação original e autonomia intelectual. Os resultados negativos advindos deste cenário educacional impactam diretamente na qualidade das investigações juscientíficas, no expediente das instituições jurídicas e na cultura em geral.

$\mathrm{Na}$ pauta de qualquer proposta séria e compromissada de reforma da educação jurídica, deve constar como prioridade a renovação da metodologia didática para superar as marcas do ensino jurídico reprodutivo e qualificar as ações educativas.

\section{Da Metodologia do Ensino Jurídico}

A educação é um processo social dinâmico de construção e aperfeiçoamento dos elementos biopsíquicos, intelectivos, axiológicos e culturais dos indivíduos de determinada comunidade. A formação educacional desenvolvida no ambiente acadêmico deve ser organizada segundo rigorosos critérios científicos e pedagógicos que objetivem elevar o nível do conhecimento e dos bens culturais por intermédio de ações educativas altamente qualificadas. De modo geral, o processo de educação constitui um eterno devir representado pela oscilação estabelecida entre a apropriação do repertório de saberes disponíveis e a superação epistêmica das fronteiras do conhecimento apreendido.

No paradigma emergente, o ato de educar ${ }^{19}$ perpassa uma concepção de ensino integrada com a pesquisa, na qual o educador deve organizar estratégias de interação do conhecimento com o educando para sustentar uma aprendizagem criativa, reflexiva e produtiva, que assuma contornos específicos de efetivo desenvolvimento intelectual. Ensinar é construir as condições materiais para consubstanciar uma experiência significativa de aprendizagem e aprimoramento do espírito cívico e investigativo das novas gerações.

\footnotetext{
${ }^{19} \mathrm{Na}$ concepção de Warat, a educação "propicia fundamentalmente el desarrollo de una metodología del aprender crítico. Educar no es suministrar información, sino facilitar el aprendizaje problematizador del aprender. Sólo de esta forma la educación deja de cumplir un mero papel socializador para pasar a ser una acción liberadora del ser humano" (1976, p. 160).
} 
Para a consecução desta finalidade, que envolve a organização das atividades a serem desenvolvidas para viabilizar a apreensão significativa dos conteúdos programados no plano de ensino, é necessário o aporte instrumental ${ }^{20}$ da metodologia didática. De acordo com Imídeo Giuseppe Nérici “a metodologia didática procura apresentar estruturações de passos de atividades didáticas que orientem adequadamente a aprendizagem do educando" (1992, p. 54). A função da metodologia didática é disponibilizar um aparato de procedimentos didáticos, constituídos de métodos e técnicas específicos, que devem sustentar positivamente a relação de ensino-aprendizagem.

Didaticamente, método quer dizer caminho para se alcançar os objetivos estipulados em um planejamento de ensino, ou caminho para se chegar a um fim. Técnica quer dizer como fazer algo. Assim, método indica o caminho e técnica mostra como percorrê-lo. Método e técnica representam a maneira de conduzir o pensamento e as ações para se atingir meta preestabelecida (NÉRICI, 1992, p. 53)

Para o desenvolvimento eficiente de um processo educacional de qualidade é requisito fundamental o suporte de uma adequada metodologia didática, pois, se o educador não realizar o planejamento das atividades didáticas ponderando os métodos e as técnicas de ensino mais apropriados a cada etapa educativa, será iminente o risco de uma aprendizagem superficial e formalista. O domínio de uma metodologia didática atualizada e dinâmica possibilita uma atuação enérgica em face das insuficiências de aprendizagem e das práticas educacionais voltadas à mera reprodução do conhecimento.

No campo do Direito os estudos concernentes ao fenômeno do ensino jurídico, da epistemologia educacional, das práticas pedagógicas e da metodologia didática constitui objeto de análise recente, o que justifica em certa medida os resultados preocupantes advindos da formação jurídica atualmente engendrada nas Faculdades de Direito. No caso específico da metodologia jusdidática, o debate contemporâneo está representado por uma perspectiva crítica $^{21}$ de problematização da validade e eficácia dos métodos aplicados no ensino jurídico e suas respectivas teorias educacionais.

\footnotetext{
${ }^{20}$ A natureza instrumental de qualquer arcabouço metodológico se justifica pela necessidade lógico-formal de organizar e sistematizar o modus operandi das formas de intelecção e produção de conhecimentos.

${ }^{21}$ Em primoroso estudo sobre as condições estruturais da educação jurídica ocidental e seus problemas metodológicos intrínsecos, Charles Eisenmann afirma: "Le problème de technique pédagogique est celui de la place à faire respectivement aux modes d'études de caractère essentiellement passif et à ceux de caractère délibérément actif, envisagés du point de vue de l'étudiant, c'est-à-dire pratiquement à l'audition de cours-monologues du professeur, d'une part, à des travaux où l'étudiant participe ou peut participer (et il est souhaité qu'il le fasse) ou qu'il effectue lui-même, d'autre part” (1954, p. 113).
} 
A premente necessidade de suprimir o modelo de educação jurídica marcado pelo predomínio de uma mentalidade didática tradicional ${ }^{22}$, que canonizou o método expositivo ritualizado na aula-conferência, por vezes, subsidiada pela técnica do código comentado ${ }^{23}$, culminou em um movimento acadêmico de inovação das fórmulas didático-metodológicas, sendo incorporados novos métodos e técnicas de ensino mais ativos, dinâmicos e que impulsionam o desenvolvimento do espírito científico dos educandos.

\begin{abstract}
A nova escola do direito tem que permitir o estabelecimento da correspondência entre a ciência (avanços científicos) e os métodos utilizados para garantir o ensino a partir das necessidades de cada país. Esta correspondência deve ser determinada por um movimento científico vinculado ao ensino contemporâneo e reconhecido como um processo de caráter científico e dialético, ou como procedimento especial de reflexo mental da realidade, por meio da ascensão do abstrato ao concreto do pensamento, em estreita relação com a formação de abstrações e generalizações de cunhos teórico e empírico. $\mathrm{O}$ ensino do direito não pode continuar sendo planejado de forma inflexível pois ele exige que os métodos utilizados pelos educadores não sejam concebidos de forma dogmática, porque a realidade jurídica avança, como avançam a tecnologia e a própria sociedade (JIMÉNEZ SERRANO \& FILHO, 2002, p. 45)
\end{abstract}

Nos últimos séculos, a exigência de superação da metodologia didática tradicional aplicada no âmbito do ensino jurídico, estimulou a composição de novas arenas educacionais alicerçadas por formas diversificadas de construção do conhecimento jurídico, que, para além do raciocínio dedutivo - típico das operações silogísticas, considera igualmente importante o raciocínio indutivo, analógico e dialético para a modelagem de novos métodos de ensino que estimulem a interação e a participação dos educandos. À luz desta tendência emergiu no circuito acadêmico mundial dois métodos didáticos amplamente conhecidos na atualidade: o case method e o problem method.

O case method é uma construção metódica de ensino sustentada originalmente ${ }^{24}$ pelo estudo de casos julgados, cuja regra didática é o desenvolvimento de uma discussão ao

\footnotetext{
${ }^{22}$ Segundo Pedro Demo: "a didática típica é o rito arcaico da aula discursiva, forjada na relação depredada e enferrujada entre alguém formalmente investido da função de ensinar e um auditório cativo, que deve apenas ouvir e copiar" (2000b, p. 53).

${ }^{23} \mathrm{O}$ uso cotidiano desta técnica de ensino produz um circular reasoning que conduz o educando a aprender apenas o conteúdo e a forma dos textos legais. Entretanto, nega a visão pluralista do fenômeno jurídico e interdita o desenvolvimento de uma formação acadêmica plena que considere os pressupostos históricos, econômicos, políticos, filosóficos, sociológicos, antropológicos, linguísticos e hermenêuticos que interagem na evolução do Direito.

${ }^{24} \mathrm{O}$ método recebeu ampla notoriedade a partir dos trabalhos desenvolvidos pelo professor Christopher Columbus Langdell da Harvard Law School, que, no século XIX, objetivava combater a metodologia de estudo típica das escolas de Direito norte-americanas, centradas no método expositivo. Para Langdell, os estudantes de direito estariam melhor preparados estudando um caso judicial e tendo que por conta própria interpretar as razões das decisões. Ao ponderar as contribuições de Langdell na popularização do case method, Jerome Hall assevera: "Langdell's accomplishment - a great achievement it was was to introduce the case method into university legal education. Its general use in American law schools is hardly more than half a century old. Many varieties have developed and it has changed and adapted itself to new conceptions of legal
} 
estilo da maiêutica socrática, na qual o docente apresenta as especificidades do caso e sua respectiva decisão, compelindo os educandos à elaboração da própria ratio decidendi. $\mathrm{O}$ método impõe ao educando a necessidade de estudar os princípios jurídicos, a legislação, os argumentos doutrinários e o repertório jurisprudencial concernente ao caso, para a produção da tese preliminar a ser debatida entre os outros estudantes, subsidiando assim sua perspectiva inicial com outros pontos de vista, ao final, na plenária, sustenta os argumentos de sua tese decisória em um debate intermediado pelo docente que analisa, discute, contradita e explica os fundamentos das teorias jurídicas subjacentes.

O problem method surgiu em meados da primeira metade do século XX como uma abordagem metodológica complementar ao case method, por meio da qual se buscava ampliar o espaço de participação do corpo discente no estudo da ciência jurídica. O método consiste na ação docente de organização esquemática de um conjunto de situações-problema a serem propostas aos educandos para que apresentem hipóteses de solução em estrita conformidade com a natureza jurídica dos problemas. A situação-problema coloca o educando em uma simulação ${ }^{25}$ da realidade profissional, na qual deve realizar uma análise das vertentes jurídicas do caso em face das teorias do direito, das nuances legais e jurisprudenciais envoltas, visando formular argumentos que justifiquem as hipóteses de solução jurídica.

A adoção do case method e do problem method combinados com técnicas de ensino dinâmicas, tais como, aula dialogada, júri simulado, dinâmicas de grupo, seminários temáticos, sustentação oral de teses jurídicas, dentre outros, possibilita a elevação da qualidade educacional das Faculdades de Direito a patamares superiores, contudo, no cenário da educação jurídica nacional estas experiências didáticas são realizadas de forma esporádica e desarticuladas sem produzir efeitos acadêmicos satisfatórios. A razão de ainda prevalecer uma mentalidade didática conservadora e ultrapassada nas instituições de ensino jurídico brasileiras, reside na falta de um consistente planejamento educacional fundado sobre uma matriz metodológica com alto grau de eficiência e excelência acadêmica.

education. Proponents of case method emphasize the participation of the student in the solution of legal problems and the pedagogic superiority of that over lecturing" (1955, p. 99).

${ }^{25}$ Em relação às vantagens do problem method para aquisição de habilidades essenciais ao exercício profissional dos juristas, Gregory Ogden assinala: "One advantage is the emphasis on training law students in lawyerlike behavior. This training includes understanding the lawyer's role as legal problem solver, exposing students to tasks similar to the real world responsibilities of lawyers, and developing the lawyer's skill of problem solving" (1984, p. 662).

R. Fac. Dir. UFG, v. 38, n. 2, p. 284-302, jul. /dez. 2014 


\section{A Pesquisa Científica como Fundamento Metodológico da Educação Jurídica}

A Universidade é o espaço social de formação superior das novas gerações que sempre deve estar sustentada por programas educacionais integrados com as atividades de pesquisa, visando à otimização de sua missão institucional de socialização do saber e produção de novos conhecimentos e recursos tecnológicos. A Universidade é guardiã do patrimônio cultural dos saberes construídos pela civilização e se encarrega da transmissão das idéias e conhecimentos historicamente consolidados, e da investigação e reexame da validade dos saberes produzidos à luz de um diálogo intertemporal, visando atualizá-los ou criar novas experiências científicas. Em razão de sua natureza institucional reservada à promoção da educação científica e dos elevados valores acadêmicos, colabora de modo especial para a edificação do futuro ${ }^{26}$ da humanidade.

A Universitas é o espaço da criação, da produção qualificada de conhecimentos, das teorias inovadoras, dos pensamentos complexos, das especulações mais sofisticadas e dos avanços no campo da ciência e da tecnologia. O aperfeiçoamento dos domínios da ciência e o desenvolvimento tecnológico tornam-se uma realidade concreta somente a partir do trabalho das pesquisas científicas ${ }^{27}$. A pesquisa é uma atividade processual de estudo e investigação dos fenômenos teóricos e empíricos de determinado campo do saber, cujo propósito é apresentar de forma lógico-sistemática uma interpretação alternativa ao objeto analisado, ou uma nova explicação teórica, um conhecimento inovador. A pesquisa científica constitui a raison d'etre da Universidade, sendo a atividade responsável pela sustentação da produção científica universitária e pela superação das fronteiras do conhecimento produzido.

As instituições de ensino superior que primam pela excelência acadêmica ${ }^{28}$ estão moduladas por uma política educacional de integração do ensino com pesquisa, que resulta

\footnotetext{
${ }^{26}$ De acordo com Edgar Morin: “A universidade conclama a sociedade a adotar sua mensagem e suas normas: ela introduz na sociedade uma cultura que não é feita para sustentar as formas tradicionais ou efêmeras do aqui e do agora, mas está pronta a ajudar os cidadãos a rever seu destino hic et nunc. A Universidade defende, ilustra e promove no mundo social e político valores intrínsecos à cultura universitária, tais como a autonomia da consciência e a problematização, o que tem como consequiência o fato de que a investigação deva manter-se aberta e plural, que a verdade tenha sempre a primazia sobre a utilidade, que a ética do conhecimento seja mantida" (2000, p. 10).

${ }^{27}$ Nas ponderações de Maria Cecília Minayo, a pesquisa constitui "atividade básica da Ciência na sua indagação e construção da realidade. É a pesquisa que alimenta a atividade de ensino e a atualiza frente à realidade do mundo. Portanto, embora seja uma prática teórica, a pesquisa vincula pensamento e ação" (1997, p. 17).

${ }^{28}$ Segundo Jiménez Serrano \& Filho: "As universidades contemporâneas têm como missão a formação de profissionais e cientistas, com a premissa de que nenhuma universidade poderá sobreviver sem produção científica e sem pesquisas.
} 
em máxima eficiência e alta performance nos rendimentos acadêmicos. A razão principal desta política institucional reside no papel da educação universitária que é desenvolver uma formação acadêmica qualificada, emancipatória e com estímulo à capacidade de produção científica autônoma. A meta da educação universitária de propiciar uma formação de elevada qualidade que possibilite o surgimento de uma mentalidade científica ${ }^{29}$ somente se sustenta em um ambiente acadêmico de educação pela pesquisa.

Educar pela pesquisa do conhecimento. Este é o meio, educação é o fim. Significa também não separar os dois componentes do mesmo todo hierárquico, ou seja, a pesquisa não se basta em ser princípio científico, pois também precisa ser princípio educativo. Não se faz antes pesquisa, depois educação, ou vice-versa, mas no mesmo processo, educação através da pesquisa (DEMO, 2000a, p. 82)

A educação pela pesquisa representa a fórmula mais autêntica e eficaz de educar, se contrapondo à dimensão receptivo-domesticadora típica das instituições de ensino superior modeladas por um projeto pedagógico tradicional que identifica no conceito de educação mera condição instrucional, de acumulação de informações e reprodução acrítica de conhecimentos. A ação pedagógica de educar pela pesquisa envolve uma formação científica altamente qualificada, balizada na reconstrução sistêmica do saber apreendido à luz do questionamento $^{30}$ e da dúvida metódica ${ }^{31}$, no predomínio de aprendizagens significativas delineadas pela autonomia intelectual e pelo esforço de elaboração de conhecimento e cultura, além da ampliação do repertório de competências e habilidades acadêmicas imprescindíveis à conduta ética e política do cidadão.

O que distingue a educação escolar e acadêmica de outras tantas maneiras de educar é o fato de estar baseada no processo de pesquisa e formulação própria. Este modo

\footnotetext{
Portanto, deve-se ter o cuidado para que a ciência e a técnica sejam o reflexo do próprio trabalho das universidades e, por consequiência, todo este processo se transforma em atividade educativa e investigativa" (2002, p. 24-25).

${ }^{29}$ A respeito da importância de perscrutar a composição de uma mentalidade científica no processo educacional, Imídeo Giuseppe Nérici afirma: “A formação da mentalidade científica é uma exigência da vida hodierna, em que o indivíduo tem de enfrentar uma conjuntura científica e sócio-econômica com tendência a complicar-se ainda mais. O homem, diante dos problemas que o cercam, não pode assumir atitude meramente contemplativa, mas sim de ação consciente, com conhecimento de causa e efeito, para que esses problemas não se agravem e não se tornem mais conflitivos. Para isso, o homem tem de assumir atitude científica, e a educação tem que formá-la" (1992, p. 18-19).

${ }^{30} \mathrm{O}$ ato de questionar as linhas de conhecimento estabelecidas é expediente necessário para validar nossos pressupostos racionais constituídos em verdade (provisória), iluminar os pensamentos e possibilitar a superação epistêmica dos saberes consolidados. Em relação a convergência do questionamento no ato da pesquisa, Pedro Demo observa que: "a pesquisa se define sobretudo pela capacidade de questionamento, que não admite resultados definitivos, estabelecendo a provisoriedade metódica como fonte principal da renovação científica" (2000b, p. 34).

${ }^{31} \mathrm{Na}$ obra Discours de la méthode (2004) Descartes argumenta que possuir uma mente dotada não é suficiente, o principal é bem aplicá-la, para tanto, é preciso conduzi-la por meio de regras fundamentais que explicitem seus fundamentos e apliquem nossas faculdades ao bom entendimento. Essas regras para a direção da mente conduzem à enunciação da dúvida metódica, que o pensador nos legou como a forma de depurar a razão de todos os elementos externos concebidos sem uma criação racional baseada no esforço metódico da dúvida, é um convite ao exercício rigoroso de pensar por si mesmo.
} 
de ver parte da definição de educação como processo de formação da competência humana, com qualidade formal e política, encontrando no conhecimento inovador a alavanca principal da intervenção ética. O critério diferencial da pesquisa é o questionamento reconstrutivo, que engloba teoria e prática, qualidade formal e política, inovação e ética. (...) O que melhor distingue a educação escolar de outros tipos de espaços educativos é o fazer-se e refazer-se na e pela pesquisa. (DEMO, 2011, p. 1-7)

A dicotomia artificial ${ }^{32}$ estabelecida entre ensino e pesquisa no âmbito de algumas instituições universitárias, especialmente no contexto juseducacional brasileiro, demonstra-se uma realidade insustentável face à razão existencial da Universidade, consubstanciada no dever de articular uma educação superior por intermédio da pesquisa do conhecimento. A pesquisa constitui a pedra angular da Universidade e justifica todas as políticas acadêmicas voltadas ao incremento de ações educativas qualificadas. Em razão de sua natureza híbrida, a pesquisa infere a noção de produção e construção científica do saber, mas, comporta também um princípio educativo ${ }^{33}$ voltado a socialização do conhecimento com base em um ensino orientado pela construção do raciocínio crítico-reflexivo e pela iniciativa investigativa.

A pesquisa como método didático ${ }^{34}$ constitui o instrumento educacional da mais alta eficiência no ambiente universitário, razão pela qual este valoroso método didático encontra-se incorporado de forma substancial no planejamento acadêmico das mais renomadas Faculdades de Direito do mundo. A pesquisa enquanto método de ensino converge todas as ações pedagógicas para o desenvolvimento de múltiplas atividades educativas com níveis excepcionais de produtividade e rendimentos acadêmicos. O método impõe ao educando a responsabilidade de elaborar um estudo científico ${ }^{35}$ sobre determinado tema, matéria ou situação-problema circunscrito pelo docente, no qual deverá pesquisar as variadas

\footnotetext{
${ }^{32}$ A respeito do desafio de sustentar a indissociabilidade do ensino com a pesquisa no âmbito universitário brasileiro, Maria Isabel da Cunha assevera que: "o ensino só será indissociado da pesquisa quando for construído um novo paradigma de ensinar e aprender na universidade. Um ensino que seja realizado com pesquisa, isto é, incorporando os processos metodológicos dessa atividade, e tendo a dúvida como referência pedagógica. Nesse caso, o aluno deverá ser o ator principal da ação e é nele que deverá acontecer o processo indissociável" (1996, p. 32).

${ }_{33}$ De acordo com Larroyo (1964) o componente técnico-educativo da pesquisa estabelece o compromisso docente de orientar todas as ações da relação ensino-aprendizagem por uma diretriz de buscas e descobertas. Para o autor, ensinar pesquisando fortalece o intelecto, desenvolve o espírito de ordem, aprimora a consciência de limitação, instiga a sinceridade e autenticidade acadêmicas e expande a mente desenvolvendo sua capacidade analítica.

${ }^{34}$ A respeito desta elaboração didática Imídeo Giuseppe Nérici destaca que: "a pesquisa como método de ensino tenta concretizar o ideal ensino-pesquisa no ensino superior, isto desde o primeiro ano de universidade" (1973, p. 260).

35 A pesquisa exige um tratamento mais profundo das questões teóricas e empíricas estudadas, diferenciando-se de uma simples atividade de leitura, interpretação e explicação articulada sem critérios de cientificidade. O estudo desenvolvido durante a atividade de pesquisa tem como característica exclusiva a racionalidade científica. Nesse aspecto, Umberto Eco responde que um estudo é científico quando: "debruça-se sobre um objeto reconhecível e definido de tal maneira que seja reconhecível igualmente pelos outros. O estudo deve dizer do objeto algo que ainda não foi dito, ou rever sob uma óptica diferente o que já se disse. O estudo deve ser útil aos demais. O estudo deve fornecer elementos para a verificação e a contestação das hipóteses apresentadas e, portanto, para uma continuidade pública” (1999, p. 21).
} 
fontes bibliográficas e técnico-científicas referentes ao assunto, e com suporte nos recursos da metodologia científica desenvolver análises, observações, reflexões, críticas e conclusões sobre as vertentes hipotéticas de explicação ou solução do assunto estudado, para formular os argumentos legitimadores de seu raciocínio.

$\mathrm{Na}$ execução do conjunto de tarefas subordinadas ao método da pesquisa o educando se apropria sistemicamente dos conteúdos estudados, possibilitando a criação de uma consistente rede de conhecimentos jurídicos. Pois, o método compele o educando ao estudo das armações teóricas do direito, dos substratos constitutivos dos princípios jurídicos, das disposições conceituais e ideológicas inseridas nas legislações, dos critérios de sustentação do corpus jurisprudencial, dos fundamentos dos costumes jurídicos, e de áreas do saber conexas ao campo do Direito. A pesquisa sustenta uma dimensão de aprendizagens sinérgicas na qual o educando interage dinamicamente com os conhecimentos teóricos, práticos e metodológicos disponíveis, empreendendo uma revisão crítica das matrizes epistêmicas vinculadas aos saberes jurídicos, para problematizar e atualizar os conhecimentos adquiridos, entreabrindo assim, espaço para a experiência científica da criação ${ }^{36}$ de novos problemas e soluções jurídicas, com níveis mais avançados e sofisticados.

A aplicação do método didático da pesquisa condiciona a instauração de ações educacionais positivas para a superação constante dos índices de desempenho acadêmico, sendo que, preliminarmente, para fins de introdução teórica e orientação das atividades a serem desenvolvidas para o estudo dos conteúdos disciplinares, podem ser ministradas algumas seções de aulas expositivas que já permitem ao docente transitar para as questões diretamente ligadas ao trabalho de pesquisa. Na aplicação do método da pesquisa podem ser combinados outros métodos didáticos ativos ${ }^{37}$ como o case method e o problem method, integrados com técnicas de ensino dinâmicas. O importante é manter a sala de aula como um laboratório aberto ao experimento da construção científica do direito, no qual a instigante

\footnotetext{
${ }^{36}$ A função criadora da ciência do direito não está reservada apenas a inovação dos artefatos científicos operacionais dos subsistemas jurídico-científicos, pois, influencia também na constituição do amálgama de questões técnicas que circundam a elaboração do próprio Direito e da vida subordinada a ele. Em relação à perspectiva de criação e evolução do Direito pela atividade da ciência jurídica, Karl Engisch assinala: "Es ist (...) der fast einzigartige Vorzug der Rechtswissenschaft unter den Kulturwissenschaften, nicht neben und hinter dem Recht einherzugehen, sondern das Recht selbst und das Leben in und unter dem Recht mitgestalten zu dürfen" (1956, p. 8).

37 Para Jiménez Serrano ativar o ensino significa: "utilizar métodos que permitam que os estudantes, de forma produtiva, descubram e se apropriem dos conhecimentos de que eles mesmos precisam para a solução dos problemas teóricos e práticos. (...) Ao se decidir sobre o uso dos métodos ativos de ensino cada docente deve lembrar que a transmissão dos conhecimentos por meio dos métodos influenciados pela reprodução verbal dos conceitos não é suficiente para formar habilidades nos estudantes e que constitui uma limitação para o desenvolvimento das capacidades investigativas" (2003, p. 49-51).
} 
ação de aprendizagem seja pautada por um ensino baseado em pesquisa e descoberta. A pesquisa confere uma nova fisionomia à relação ensino-aprendizagem, em que o papel docente não está reduzido à simplificação e entrega de conteúdos, mas, ao status de mediador ${ }^{38}$ qualificado na interlocução do educando com os domínios da ciência jurídica.

O ensino com pesquisa plasma uma atmosfera acadêmica altamente produtiva para as Faculdades de Direito ao franquear um espaço de formação científica pluralista e multicultural, no qual os estudantes são os agentes responsáveis pelo desenvolvimento de seus processos educacionais, recebendo forte incentivo institucional para o exercício da autonomia intelectual, a produção de conhecimentos e o aperfeiçoamento de múltiplas competências e habilidades acadêmicas. O docente é entendido como profissional da educação pela pesquisa que sustenta seus saberes científicos na pesquisa para atualização permanente, a rigor é um professor-pesquisador respeitado pela atuação na transformação do tecido sociopolítico. Nesse ambiente acadêmico, a pesquisa realiza a ativação dos mecanismos didáticos e se converte no fundamento metodológico da educação jurídica, resultando no alto padrão de formação jurídica das futuras gerações e na elevação da qualidade da pesquisa juscientífica, da literatura jurídica especializada e da cultura em geral.

\section{Considerações Finais}

Na conjuntura atual marcada pela influência predominante dos avanços da ciência e tecnologia na organização da sociedade da informação e do conhecimento, é de suma importância a atualização qualificada dos programas educativos das instituições universitárias para propiciar uma formação científica de alto grau, aliada ao imperativo da responsabilidade social, e que supere as tensões do mercado globalizado. Nesse contexto, a educação jurídica brasileira urge de modificações estruturais, especialmente na política didático-pedagógica que é a grande responsável pela reprodução de um modelo incompetente de formação jurídica. À luz da epistemologia educacional e dos fundamentos teóricos da didática moderna, pensamos que a pesquisa científica constitui o mais eficiente e completo método de ensino. A pesquisa é

\footnotetext{
${ }^{38}$ A respeito do trabalho docente em uma metodologia de ensino pela pesquisa, Pedro Demo escreve que: "O professor tem seu lugar, como pesquisador e orientador, para motivar no aluno o surgimento do novo mestre. Faz parte do conceito de criatividade, 'saber se virar', inventar saídas, sobretudo 'aprender a aprender', e isto é profundamente pesquisa. A postura de mero ensino e mera aprendizagem é mais cômoda, menos problemática, evita o confronto produtivo entre mestre maduro e mestre em gestação. Todavia, predomina aí o lado da 'imbecilização' útil, enquanto na relação de pesquisa científica e educativa pode predominar o lastro da emancipação" (2000b, p. 64-65).
}

R. Fac. Dir. UFG, v. 38, n. 2, p. 284-302, jul. /dez. 2014 
a instrumentação que dá identidade e sentido a educação universitária, portanto, somente com a construção de uma plataforma educacional fundada sobre uma matriz metodológica de ensino pela pesquisa é que as Faculdades de Direito do país poderão formar com níveis de excelência acadêmica os novos juristas aptos a pensar, com versatilidade científica, soluções inovadoras em face das múltiplas complexidades e incertezas do futuro.

\section{Referências Bibliográficas}

ADEODATO, João Maurício. Formação universitária, exercício profissional e especialização na área do direito. Revista Múltipla. Brasília. Ano XII. vol. 16. n. 22. p. 131-144. Junho. 2007.

CALERA, Nicolás María Lópes. La crisis de las Facultades de Derecho: una cuestión ideológica. Anales de la Cátedra Francisco Suarez. Granada. n. 20-21. p. 1-42. 1980-1981.

CHAUÍ, Marilena de Souza. Escritos sobre a universidade. São Paulo: ed. Unesp, 2001.

CUNHA, Maria Isabel da. Ensino com Pesquisa: A prática do professor universitário. Cadernos de Pesquisa. São Paulo. n. 97. p. 31-46. Maio. 1996.

DESCARTES, René. Discours de la méthode. In: DESCARTES. Oeuvres et lettres. Paris: Gallimard, 2004.

DEMO, Pedro. Educar pela pesquisa. 9. ed. revista. Campinas, SP: Autores Associados, 2011.

Educar pela pesquisa. 4. ed. Campinas, SP: Autores Associados, 2000a.

Pesquisa: princípio científico e educativo. 7. ed. São Paulo: Cortez, 2000 b.

ECO, Umberto. Como se faz uma Tese. 15. ed. São Paulo: Perspectiva, 1999.

EISENMANN, Charles. Les sciences sociales dans l'enseignement supérieur: Droit. Paris: Unesco, 1954.

ENGISCH, Karl. Einführung in das juristische Denken. Stuttgart: W. Kohlhammer Verlag, 1956.

FARIA, José Eduardo. A reforma do ensino jurídico. Porto Alegre: Sergio Antonio Fabris Editor, 1987.

FILHO, Álvaro Melo. Ensino Jurídico e a Nova LDB. In: CONSELHO FEDERAL DA OAB. Ensino Jurídico OAB: 170 anos de cursos jurídicos no Brasil. Brasília, DF: OAB, Conselho Federal, 1997. 
GUSTIN, Miracy Barbosa de Sousa; DIAS, Maria Tereza Fonseca. (Re) Pensando a Pesquisa Jurídica: teoria e prática. Prefácio José Eduardo Faria. Belo Horizonte: Del Rey, 2002.

HALL, Jerome. Teaching Law by Case Method and Lecture. Society of Public Teachers of Law. Annual meeting of the Society of Public Teachers of Law. Edinburgh. p. 99-106. July. 1955.

JiMÉnEZ SERRANO, Pablo. Metodologia do Ensino e da Pesquisa Jurídica: manual destinado à requalificação da atividade docente e da pesquisa científica nas universidades. Prefácio Paulo Q. Marques. Barueri, SP: Manole, 2003.

JIMÉNEZ SERRANO, Pablo; FILHO, Heitor Pinto. Excelência Universitária e o Ensino do Direito. São Paulo: Julgar, 2002.

LARROYO, Francisco. Pedagogía de la enseñanza superior. México: Editorial Porrua, 1964.

MACHADO, Nílson José. Epistemologia e Didática: as concepções de conhecimento e inteligência e a prática docente. São Paulo: Cortez, 1995.

MINAYO, Maria Cecília de Souza (Org.). Pesquisa Social: teoria, método e criatividade. 7. ed. Petrópolis: Vozes, 1997.

MORIN, Edgar. Complexidade e transdisciplinaridade: a reforma da universidade e do ensino fundamental. Natal: EDUFRN, 2000.

Introdução ao pensamento complexo. 4. ed. Lisboa: Instituto Piaget, 2003.

NÉRICI, Imídeo Giuseppe. Metodologia do Ensino: Uma introdução. 4. ed. São Paulo: Atlas, 1992.

de Cultura S. A., 1973.

Metodologia do Ensino Superior. 2. ed. Rio de Janeiro: Fundo

OGDEN, Gregory L. The Problem Method in Legal Education. Journal of Legal Education. Association of American Law Schools. vol. 34. n. 4. p. 654-673. December. 1984.

PHELPS, Edward J. Methods of Legal Education. Yale Law Journal. vol. I. n. 4. p. 139-161. March. 1892.

PIMENTA, Selma Garrido; ANASTASIOU, Léa das Graças Camargos. Docência no ensino superior. São Paulo: Cortez, 2002.

PÔRTO, Inês da Fonseca. Ensino jurídico, diálogos com a imaginação: construção do projeto didático no ensino jurídico. Porto Alegre: Sergio Antonio Fabris Editor, 1987. 
RODRIGUES, Horácio Wanderlei. Novo Currículo Mínimo dos Cursos Jurídicos. São Paulo: Revista dos Tribunais, 1995.

WARAT, Luis Alberto. El derecho y su lenguaje: elementos para una teoria de la comunicación jurídica. Buenos Aires: Cooperadora de derecho y ciencias sociales, 1976.

Fundação Boiteux, 2004.

Epistemologia e Ensino do Direito: o sonho acabou. Florianópolis:

ZIPPELIUS, Reinhold. Allgemeine Staatslehre. 13. Aufl. München: Beck, 1999. 